\title{
Event-related potentials (ERP) and SGIP1 gene polymorphisms in alcoholics: relation to family history of alcoholism and drug usage
}

\author{
Roman Chwedorowicz', Grzegorz Raszewski², Lucyna Kapka-Skrzypczak³ , Krzysztof Sawicki ${ }^{3}$, \\ Tadeusz Studziński' \\ ${ }^{1}$ Department of Neurodegenerative Diseases, Institute of Rural Health, Lublin, Poland \\ ${ }^{2}$ Department of Physiopathology, Institute of Rural Health, Lublin, Poland \\ ${ }^{3}$ Department of Molecular Biology and Translational Research, Institute of Rural Health, Lublin, Poland
}

Chwedorowicz R, Raszewski G, Kapka-Skrzypczak L, Sawicki K, Studziński T. Event-related potentials (ERP) and SGIP1 gene polymorphisms in alcoholics: relation to family history of alcoholism and drug usage. Ann Agric Environ Med. 2016; 23(4): 618-624. doi: 10.5604/12321966.1226856

\begin{abstract}
Objective. The electrophysiological characteristics may serve as valuable biomarkers for the genetic vulnerability underlying alcoholism. The purpose of this study was to evaluate the potential associations between single nucleotide polymorphisms (SNPs) located in the SGIP1 gene and the theta ERP quantitative traits.

Method. The theta band $(4-7 \mathrm{~Hz})$ visual ERP occurring in the P300 response in the resting EEG were examined to explore the electrophysiological effects of alcohol on the brain in five regions: frontal, central, parietal, temporal and occipital in patients with alcohol addiction. In addition, we tested the potential associations between single nucleotide polymorphisms (SNPs) located in the SGIP1 gene and ERP quantitative traits.

Results. We found that the amplitude of the auditory P300 response differed considerably among groups of alcoholics in the frontal, central and temporal areas of the brain and it was lower in the studied brain regions in alcoholics in comparison to non-alcoholics. However, among subjects in the young adult group (GR-1) there was no statistical difference in amplitude of P300 response with control subjects in all studied brain regions in comparison with non-alcoholics.

Moreover, we revealed that SNP rs10889635 had a significant effect on P300 amplitude in the central and temporal regions. The reduced P300 amplitude was in AA carriers in comparison to both carriers of GG and GA alleles.

Conclusion. The present study demonstrated a possible association of target P300 evoked theta and of alcohol dependence with SNPs from the gene SGIP1 in the region of rs10889635, but further studies are required.
\end{abstract}

- Key words

Alcohol dependence, Event-related potentials, Resting theta EEG power, SGIP1 SNPS

\section{INTRODUCTION}

Alcoholism is a neuropsychiatric disorder with multiple etiological contributions from genetic and environmental factors, along with their interactions $[1,2]$. A variety of evidence [3] suggests that family history of alcoholism significantly increases the risk for the development of alcohol use disorders (AUDs). Thus, it is critical to understand the neurobiological underpinnings that contribute towards the heritability of the disorder. There is ample evidence that brain electrical activity is hereditary and that some electrophysiological characteristics observed in alcoholics are already present in their offspring prior to exposure to alcohol or drugs. Thus, these electrophysiological characteristics may serve as valuable biomarkers for the genetic vulnerability underlying alcoholism [4]. As demonstrated, electrophysiological measures of brain function have served as effective "endophenotypes" that are correlated with alcoholism and are involved in the pathway between genotype and alcoholism $[3,5]$.

The strategy of using EEG measures as endophenotypes in the search for genes involved in alcoholism has already been

Address for correspondence: Roman Chwedorowicz, Department of Neurodegenerative Diseases, Institute of Rural Health, 20-090 Lublin, Jaczewskiego 2, Poland

E-mail: chwedorczukimw@wp.pl

Received: 20 October 2016; accepted: 12 December 2016 successfully implemented. Data from the Collaborative Study on the Genetics of Alcoholism (COGA) (consisting of families in which a proband and two additional first-degree relatives are affected with alcohol dependence) indicate that EEG traits for an individual are stable, variable between individuals, and heritability of EEG spectral power is uniformly high for all wave forms.

In a study by Hodgkinson et al. [6], three genes (SGIP1, ST6GALNAC3 and UGDH) with nominal association to variability of theta and alpha waves were found. The study also showed an association of SGIP1 with alcoholism, an effect that may be mediated via the same brain mechanisms accessed by the theta EEG, and which also provides validation for the use of EG as an endophenotype for alcoholism. Several significant single-nucleotide polymorphisms (SNPs), located in the SGIP1 gene (chromosome 1p31.3) showed association with resting theta electroencephalogram (EEG) power and of these, rs6588207 and rs10889635 were reported as modestly associated with alcohol use disorders [6].

Our study examines the differences in the theta band (4-7 Hz) ERP occurring in the P300 response in the resting EEG of alcoholics in comparison to normal ageand sex-matched control subjects. Also, we investigated the distribution of rs6588207 and rs10889635 genotypes in cases and control groups to confirm whether it contributes to the risk of alcoholism risk in families with a positive diagnosis of alcohol dependence. 


\section{METHOD AND MATERIALS}

\section{Subjects}

All participants (18-72 years old) were recruited throughout the local community. The study included individuals of Polish ancestry with three generations (parents, siblings, spouses, marrying into the family, and children). The alcoholic group consisted of 108 individuals from families with a positive diagnosis of alcohol dependence. The control group consisted of 25 unaffected individuals from families who were screened and assessed to be negative for a diagnosis of alcohol dependence.

We detailed individuals as having a positive family history of alcoholism (FHP) if they had at least one biological parent or 2 or more second-degree relatives diagnosed with AUDs, while family history negative (FHN) individuals had an absence of familial alcoholism in first and second-degree relatives [7]. Subjects were excluded from neurophysiological assessment if they had any of the following: 1) hepatic encephalopathy or cirrhosis of the liver; 2) significant head injury or seizures; 3) acute or chronic illness that affect brain function. They were also excluded if they had used medication known to influence brain functioning or had used psychoactive substances in the past 7 days.

The alcoholic group was further subdivided into 5 distinct groups based on the criteria for alcohol dependence according to the National Institute on Alcohol Abuse and Alcoholism (NIAAA): young adult subtype (GR-1); young antisocial subtype (GR-2); functional subtype (GR-3); intermediate familial subtype (GR-4) and chronic severe subtype (GR5) (Tab. 1). The experimental protocols were approved by the Ethics Committee of the Institute of Rural Health in Lublin, Poland, after obtaining informed consent from all participants.

\section{EEG data acquisition and signal analysis}

Subjects sat in a dimly lit sound-proof chamber. Electroencephalographic (EEG) activity was recorded with an electrode cap from 19 electrode sites in five brain regions: frontal (F3, F4, F7, F8, Fp1, Fp2 and Fz), central (C3, C4, and $\mathrm{Cz}$ ), parietal (P3, P4 and Pz), temporal (T3, T4, T5, T6) and occipital (O1 and $\mathrm{O} 2)$. The nose served as a reference and the forehead served as a ground. All subjects performed an auditory choice reaction time (RT) task, during which ERPs were recorded. ERPs were elicited with two tones of different frequencies. One stimulus was a low tone $(600 \mathrm{~Hz})$ and the other a high tone $(1600 \mathrm{~Hz})$. Each stimulus were randomly generated by a tone generator and presented every $3 \mathrm{sec}$. The tones had a $60 \mathrm{~ms}$ duration with a $2 \mathrm{~ms}$. rise and fall time, at an intensity of $90 \mathrm{dBA}$. The auditory stimuli were presented through headphones.

Electrical activity was measured using Neuroscan amplifiers and was recorded continuously over a bandwidth of $0.02-100 \mathrm{~Hz}$ on a Neuron-Spectrum-5 system (Neurosoft, Inc., El Paso, TX, USA) at sampling rates of $500 \mathrm{~Hz}$ and stored for further analysis. The bandpass was filtered between 0.5 and $35.0 \mathrm{~Hz}$.

ERP characteristics, including P300, were evaluated in members of 3 generations (parents, siblings, spouses, marrying into the family, and children) in 2 independent samples.

\section{Genotyping}

Genomic DNA isolation was extracted from $0.2 \mathrm{ml}$ of whole human blood by QIAamp DNA Blood Mini Kit (QIAGEN, USA) according to the producer's instructions.

Genotyping was performed on an Applied Biosystems 7500 FAST Real-Time PCR System (Foster City, CA, USA) using a TaqMan SNP genotyping assay (Affymetrix Inc., Cleveland, Ohio, USA). Each reaction $(10 \mathrm{ml})$ contained a $5 \mathrm{ml}$ TaqMan Genotyping master mix, $0.5 \mathrm{ml}$ primers and probes (Applied Biosystems), $2.5 \mathrm{ml}$ water and $2 \mathrm{ml} \mathrm{DNA}$ $(15-25 \mathrm{ng} / \mathrm{ml})$. Cycling conditions were as follows: $95^{\circ} \mathrm{C}$ for $10 \mathrm{~min} ; 50 \mathrm{cycles}$ of $92^{\circ} \mathrm{C}$ for $15 \mathrm{sec}$ and $60^{\circ} \mathrm{C}$ for $90 \mathrm{sec}$. Fluorescence was detected during the $60^{\circ} \mathrm{C}$ annealing step of each PCR cycle.

SNP-s were identified in intron gene SGIP1 in the region of rs 6588207 and in the region of rs10889635.

\section{Enzymatic profile}

Enzimatic profile was determined using an automatic biochemistry analyser (Express Plus, Chiron Diagnostics, USA), with reagents by Siemens (Siemens Healthcare Diagnostics, Tarrytown, NY, USA), according to the procedure provided by the manufacturer. The following enzymes were determined in blood serum: alanine aminotransferase (ALAT); aspartate aminotransferase (AST); gamma-glutamyl transpeptidase (GGTP) and alkaline phosphatase (ALP).

\section{Statistical analysis}

Our objective was to compare the absolute power of the theta band $(3-7 \mathrm{~Hz})$ in the resting EEG between alcoholic and control subjects. Data were expressed as the mean \pm standard deviation (SD) or median (range) according to data Distribution. A Kruskal-Wallis non-parametric ANOVA and Dunn's multiple comparisons test were applied to analyse data from both P300 amplitude, P300 latency, and from the enzymatic tests in study groups.

Bonferroni's Multiple Comparison Test was used to study SGIP1 effects on P300 amplitude and latency in alcoholics.

In the genetic study, the Hardy-Weinberg equilibrium was tested using a Pearson chi squared test. The odds ratio (OR) and its $95 \%$ confidence interval $(95 \% \mathrm{CI})$ were obtained by logistic regression methodology to determine correlations between the SGIP1 polymorphism, and alcoholics groups.

\section{RESULTS}

\section{The study population}

Characteristics of the study population with a division into 5 groups based on the criteria for alcohol dependence according to NIAAA are detailed in Table 1.

Persons in the young adult subtype (GR-1) had a low rate of family alcoholism (22.7\%) and co-occurring drugs abuse (13.6\% for smoked tobacco and $18.2 \%$ for psychoactive drugs). The mean age of participants was 31.1 \pm 9 .0. In both groups (GR-1 and GR-2), the studied participants were matched for age, sex, education, kinship and domicile.

The young antisocial subtype (GR-2) consisted mostly of young individuals (32 \pm 7.98 years) who mostly $(62.5 \%)$ had a positive family history of alcoholism (FHP). In this group, 23\% had antisocial personality disorder, more than $68 \%$ smoked tobacco and many $(70.8 \%)$ had problems with psychoactive drugs. 
Table 1. Characteristics of the study population

\begin{tabular}{|c|c|c|c|c|c|c|}
\hline Characteristic & $\begin{array}{l}\text { GR-1 } \\
n=22\end{array}$ & $\begin{array}{l}\text { GR-2 } \\
n=24\end{array}$ & $\begin{array}{l}G R-3 \\
n=31\end{array}$ & $\begin{array}{l}G R-4 \\
n=26\end{array}$ & $\begin{array}{l}G R-5 \\
n=24\end{array}$ & $\begin{array}{c}\text { Control } \\
n=25\end{array}$ \\
\hline Age; years $( \pm S D)$ & $31.07(9.0)$ & $32.2(7.98)$ & $52.86(6.91)$ & $57.61(7.54)$ & $59.0(6.26)$ & $47.0(7.23)$ \\
\hline Smokers; yes, \% & 18.18 & 58.33 & 38.71 & 69.23 & 79.16 & 16.0 \\
\hline Treatment of alcohol dependence: yes, \% & 4.54 & 25.0 & 12.9 & 23.0 & 58.33 & 0.0 \\
\hline Psychiatric disorders: yes, $\%$ & 0.0 & 0.0 & 9.67 & 26.92 & 33.33 & 0.0 \\
\hline Use of psychoactive drugs: yes, $\%$ & 13.6 & 70.83 & 19.35 & 26.92 & 41.67 & 4.0 \\
\hline Family history of alcoholism: yes, $\%$ & 22.72 & 62.5 & 12.9 & 61.53 & 75.0 & 8.0 \\
\hline $\begin{array}{l}\text { City residents } \\
\text { yes, } \%\end{array}$ & 72.72 & 75.0 & 51.61 & 53.84 & 70.83 & 64.0 \\
\hline $\begin{array}{l}\text { Education: } \\
>12 \text { years, yes, } \%\end{array}$ & 22.72 & 16.67 & 25.8 & 15.38 & 8.33 & 32.0 \\
\hline
\end{tabular}

Older people were in the next groups (Gr-3, Gr-4 and Gr-5) and their age averaged: $52.86 \pm 6.98 ; 57.61 \pm 7.54 ; 59.0$ \pm 6.26 , respectively.

Participants with GR-3, who were functional alcoholics, were well-educated (more than one-quarter had higher education) and mainly lived in towns (70.8\%). The interview established that they had stable jobs and families. About $13 \%$ had a FHP, several people had had a major depressive illness sometime in their lives, nearly $39 \%$ were smokers and about $20 \%$ were taking psychoactive drugs.

Alcoholics in this subtype (GR-4) mostly started drinking early (the average was about 16 years of age). More than half (61.5\%) had close relatives who were alcoholics and $43 \%$ had had depressive illness. Most of these individuals smoked cigarettes (69.2) and nearly one in 5 (19.8\%) had problems with psychoactive drugs.

The chronic severe subtype (GR-5) was comprised of individuals who had early onset of drinking and alcohol problems (the average was about 14 years of age) with high rates of Antisocial Personality Disorder (21.6\%) and criminality (5.8\%). Almost $75 \%$ had families with multigenerational alcoholism. They had also other psychiatric disorders, including depression (23.4\%), bipolar disorder (3.2\%) and anxiety disorders (12.6\%), as well as high rates of smoking (79.2\%), and psychoactive dependence (61.6\%). Nearly 59\% of these alcoholics sought help for their drinking problems.

\section{Results of indicator enzyme activity}

The traditional indirect blood alcohol markers GGT, AST, ALT and ALP were analyzed in the laboratory of the Institute of Rural Health, Lublin, Poland (Tab. 2).

We found that ALT, GGTP and ALP values differed considerably among the 5 alcoholic groups $(\mathrm{H}=12.48$, $\mathrm{p}=0.0287 ; \mathrm{H}=18.02, \mathrm{p}=0.0029$ and $\mathrm{H}=13.74, \mathrm{p}=0.0173$, respectively). AST value did not differ considerably among the groups $(\mathrm{H}=8.811 ; \mathrm{p}=0.1168)$.

In addition, the alcoholics in the young adult subtype (GR-1) had a lower GGTP level than those from the GR-2, GR-3 and Gr-4 groups $(\mathrm{p}<0.05)$ and a higher ALP value than those from the Gr-4 group ( $\mathrm{p}<0.05)$. There were no differences in the analyzed parameters between the treatment groups and the control group.
Table 2. Results of indicator enzyme activity in treatment groups and control

\begin{tabular}{lcccc}
\hline Participants & $\mathrm{ALT} ; \mathrm{U} / \mathrm{L}$ & $\mathrm{AST} ; \mathrm{U} / \mathrm{L}$ & $\mathrm{GGTP} ; \mathrm{U} / \mathrm{L}$ & $\mathrm{ALP} ; \mathrm{U} / \mathrm{L}$ \\
\hline $\mathrm{M}( \pm \mathrm{SD})$ & $\mathrm{M}( \pm \mathrm{SD})$ & $\mathrm{M}( \pm \mathrm{SD})$ & $\mathrm{M}( \pm \mathrm{SD})$ \\
\hline $\mathrm{Gr}-1$ & $21.0(9,0)$ & $22.9(5.2)$ & $21.5(9.3)$ & $72.3(11.8)$ \\
$\mathrm{M}=22$ & $\mathrm{M}=22$ & $\mathrm{M}=21$ & $\mathrm{M}=72$ \\
\hline $\mathrm{Gr}-\mathbf{3}$ & $45.8(49.9)$ & $44.3(36.1)$ & $53.2(39.6)^{*}$ & $65.3(17.9)$ \\
& $\mathrm{M}=26$ & $\mathrm{M}=29$ & $\mathrm{M}=42$ & $\mathrm{M}=71$ \\
\hline $\mathrm{Gr}-\mathbf{4}$ & $29.1(9.11)$ & $25.8(6.3)$ & $34.1(25.7)$ & $58.9(14.1)$ \\
\hline & $\mathrm{M}=30.5$ & $\mathrm{M}=26.5$ & $\mathrm{M}=29$ & $\mathrm{M}=60.5$ \\
\hline Gr-5 & $33.1(23.5)$ & $33.7(29.7)$ & $63.1(98.3)^{*}$ & $54.3(14.8) * *$ \\
\hline $\mathrm{P}=$ & $\mathrm{M}=34$ & $\mathrm{M}=27$ & $\mathrm{M}=46$ & $\mathrm{M}=50$ \\
$\mathrm{H}=$ & $34.8(25.9)$ & $37.4(29.1)$ & $138.1(276.2)^{*}$ & $60.9(20.7)$ \\
\hline Control & $\mathrm{M}=26$ & $\mathrm{M}=26$ & $\mathrm{M}=53$ & $\mathrm{M}=61$ \\
\hline & $\mathbf{0 . 0 2 8 7}$ & 0.1168 & $\mathbf{0 . 0 0 2 9}$ & $\mathbf{0 . 0 1 7 3}$ \\
\hline $\mathrm{H}=\mathbf{1 2 . 4 8}$ & $\mathrm{H}=8.81$ & $\mathbf{H}=\mathbf{1 8 . 0 2}$ & $\mathbf{H = 1 3 . 7 4}$ \\
\hline
\end{tabular}

$\mathrm{M}$ - mean, $\mathrm{SD}$ - standard deviation, $\mathrm{Me}$ - median, $\mathrm{H}$ - Kruskal-Wallis test, $\mathrm{p}$ - level of significance; *Significant as compared with group I (Dunn's multiple comparisons test).

\section{P300 response recorded as latency and amplitude theta EEG}

Of the 19 electrodes of leads, we used bipolar recordings with sensors placed over the FP1, FP2 (left, right frontal); C3, C4 (left, right central); O1, O2 (left, right occipital) and T3, T4 (left, right temporal) regions.

The P300 component was defined as the largest positivegoing peak, occurring within $300-800 \mathrm{~ms}$ at each electrode. Peak amplitude was measured relative to the pre-stimulus baseline, and peak latency was measured from the time of stimulus onset.

The mean amplitude and latency of evoked P 300 potential for each alcoholic group and the control group are presented in Table 3.

It was shown that the latency of the auditory $\mathrm{P} 300$ response to low and high pitch stimulation did not differ between the patients and the control subjects in all investigated brain areas. However, the amplitude of the auditory P300 response in central areas of the brain $(\mathrm{C} 3, \mathrm{C} 4)$ were lower in alcoholics of all studied groups in comparison to the control subjects, with the exception of the young adult subtype (GR-1), ( $\mathrm{p}<$ 0.05). Furthermore, in the young adult group, there was no statistical difference in the amplitude of $\mathrm{P} 300$ response 
Table 3. Mean amplitude and latency of evoked P300 potential

\begin{tabular}{|c|c|c|c|c|c|c|c|c|}
\hline $\begin{array}{c}\text { Brain } \\
\text { Regions }\end{array}$ & $\begin{array}{c}\text { GR-1 } \\
n=22\end{array}$ & $\begin{array}{c}\text { GR-2 } \\
n=24\end{array}$ & $\begin{array}{c}\text { GR-3 } \\
n=31\end{array}$ & $\begin{array}{c}\text { GR-4 } \\
n=26\end{array}$ & $\begin{array}{l}G R-5 \\
n=24\end{array}$ & $\begin{array}{c}\text { Control } \\
n=25\end{array}$ & $P=$ & $\mathrm{H}=$ \\
\hline \multicolumn{9}{|c|}{ Latency $[\mathrm{ms}] \mathrm{M} \pm(\mathrm{SD})$} \\
\hline FP2-R & $315.4(22.4)$ & $292.6(34.5)$ & $303.2(40.8)$ & $298.1(25.6)$ & $301.4(32.2)$ & $306.0(32.1)$ & 0.4153 & 5.004 \\
\hline C3-R & $297.3(22.2)$ & $287.6(28.4)$ & $305.1(30.2)$ & $293.7(23.8)$ & $290.3(24.2)$ & $303.0(28.3)$ & 0.2368 & 6.789 \\
\hline C4-R & $301.4(25.8)$ & $289.0(29.5)$ & $303.1(25.6)$ & $294.7(27.6)$ & $288.2(26.2)$ & $301.4(25.6)$ & 0.3634 & 5.451 \\
\hline O1-R & $298.9(20.8)$ & $306.7(36.6)$ & $298.6(31.2)$ & $303.2(30.5)$ & $295.6(32.3)$ & $298.0(31.2)$ & 0.7745 & 2.513 \\
\hline $\mathrm{O} 2-\mathrm{R}$ & $290.7(21.8)$ & $299.1(34.1)$ & $286.9(23.9)$ & $288.5(25.3)$ & $298.5(30.5)$ & $308.6(22.5)$ & 0.1630 & 7.880 \\
\hline T3-R & $304.0(26.1)$ & $288.1(29.1)$ & $305.6(44.2)$ & $288.0(22.9)$ & $301.1(24.7)$ & $302.9(30.0)$ & 0.0656 & 10.36 \\
\hline T4-R & $311.0(28.9)$ & $282.7(31.7)$ & $304.3(35.9)$ & $296.2(30.8)$ & $294.6(26.7)$ & $298.6(26.2)$ & 0.1736 & 7.770 \\
\hline \multicolumn{9}{|c|}{ Amplitude $[\mu \mathrm{V}] \mathrm{M} \pm(\mathrm{SD})$} \\
\hline FP-R & $4.48(2.42)$ & $3.33(2.39)$ & $3.43(1.97)$ & $3.29(1.62)$ & $3.36(1.42)$ & $4.38(1.69)$ & 0.1614 & 7.907 \\
\hline FP2-R & $3.97(2.03)$ & $3.19(2.61)$ & $2.98(1.56)$ & $3.10(1.60)$ & $3.22(1.34)$ & $4.99(2.57)$ & 0.0403 & 11.63 \\
\hline C3-R & $6.72(4.29)$ & $3.24(2.85)$ & $3.13(1.88)$ & $2.66(1.17)$ & $2.24(0.79)$ & $7.37(3.46)$ & $<0.0001$ & 36.75 \\
\hline C4-R & $6.24(3.68)$ & $3.17(2.18)$ & $3.78(2.18)$ & $3.22(1.96)$ & $2.80(1.67)$ & $6.74(2.51)$ & $<0.0001$ & 27.93 \\
\hline O1-R & $2.58(3.05)$ & $2.86(1.44)$ & $3.21(2.63)$ & $3.83(2.26)$ & $3.62(1.88)$ & $3.27(1.68)$ & 0.1353 & 8.405 \\
\hline $\mathrm{O} 2-\mathrm{R}$ & $2.99(2.18)$ & $3.27(1.93)$ & $3.12(1.73)$ & $3.53(2.13)$ & $3.38(2.32)$ & $3.42(1.84)$ & 0.9494 & 1.152 \\
\hline T3-R & $5.71(3.77)$ & $4.07(1.48)$ & $3.43(1.61)$ & $2.44(1.50)$ & $2.22(0.84)$ & $7.10(3.50)$ & $<0.0001$ & 42.22 \\
\hline T4-R & $4.17(2.73)$ & 3.79 (1.77) & $3.16(1.60)$ & $3.07(1.61)$ & $2.24(1.11)$ & $5.71(2.83)$ & 0.0008 & 20.96 \\
\hline
\end{tabular}

$\mathrm{M}$ - mean, SD - standard deviation, $\mathrm{H}$ - Kruskal-Wallis test, $\mathrm{p}$ - level of significance.

with control subjects in all studied brain regions. Similarly, a reduced amplitude of the $\mathrm{P} 300$ also occurred in temporal region (T3, T4) in the intermediate familial subtype (GR-4) and chronic severe subtype (GR-5) or in the $\mathrm{T} 3$ region in the functional subtype (GR-3) in comparison to non -alcoholics.

Moreover, it turned out that the amplitude of the auditory P300 response differed considerably among the 5 alcoholic groups: in the following regions: frontal (FP2-R; $\mathrm{H}=11.63$; $\mathrm{p}=04.03)$; central $(\mathrm{C} 3, \mathrm{C} 4 ; \mathrm{H}=36.75,27.93 ; \mathrm{p}<0.0001)$ and temporal (T3, T4; $\mathrm{H}=42.22,20.96 ; \mathrm{p}<0.0001, \mathrm{p}=0.0008$ ), respectively.

In central brain areas $(\mathrm{C} 3, \mathrm{C} 4)$ in the familial subtype group (GR-4), as well as in the chronic severe subtype group (GR-5), the P300 amplitudes were 2.66; 3.22 and 2.24; 2.81 and were significantly lower than in the young adult subtype (6.725 and 6.241 $\mu \mathrm{V} ; \mathrm{p}<0.01$ ), respectively. Similar differences in the amplitude value of P300 between G-1 and G-4/G-5 $(\mathrm{p}<0.05)$ were found in the temporal region $(\mathrm{T} 3, \mathrm{~T} 4)(\mathrm{Tab} .3)$.

\section{Effect of Genotype on P300 Indices}

\section{SGIP1 effects on P300 Amplitude.}

SNP rs10889635 had a significant effect on P300 amplitude in the central (C3-R, C4-R) and temporal (T3, T4) regions. Those homozygous for the A allele had a reduced P300 amplitude in comparison with those homozygous for the $G$ allele (Diff $-1.538 \mu \mathrm{V}$; 95\% CI: -2.964 to $-0.117 \mu \mathrm{V}$; $\mathrm{P}<0.05$ ) and the heterozygous group GA (Diff $-1.590 \mu \mathrm{V} ; 95 \% \mathrm{CI}$ : -2.965 to $-0.524 \mu \mathrm{V} ; \mathrm{P}<0.01$ ), for C3-R and for C4-R (Diff $-1,44 \mu \mathrm{V} ; 95 \% \mathrm{CI}:-2.727$ to $-0.1623 \mu \mathrm{V} ; \mathrm{P}<0.05$ ) and (Diff $-1,262 \mu \mathrm{V} ; 95 \% \mathrm{CI}:-2.203$ to $-0.320 \mu \mathrm{V} ; \mathrm{P}<0.05)$, respectively.

A similar relationship was found in the temporal area (T3, T4). The reduced P300 amplitude was in AA carriers in comparison to carriers of the GG allele (Diff $-1.964 \mu \mathrm{V}$; 95\% CI: -3.365 to $-0.564 \mu \mathrm{V} ; \mathrm{P}<0.01)$ and to carriers of the GA allele (Diff $-1,087 \mu \mathrm{V} ; 95 \%$ CI: -2.132 to $-0.0408 \mu \mathrm{V} ; \mathrm{P}<$
0.05 ) for $\mathrm{T} 3$ region and for $\mathrm{T} 4$ region (Diff $-1.209 \mu \mathrm{V} ; 95 \%$ CI: -2.407 to $-0.012 \mu \mathrm{V} ; \mathrm{P}<0.05$ ) and (Diff $-1.697 \mu \mathrm{V} ; 95 \%$ CI: -2.591 to $-0.828 \mu \mathrm{V} ; \mathrm{P}<0.001)$, respectively. The SNP rs 6588207 were not associated with P300 amplitude (Tab. 4).

Table 4. P300 Amplitude by Genotype Group

\begin{tabular}{|c|c|c|c|c|c|c|c|c|c|c|}
\hline \multirow{2}{*}{$\begin{array}{l}\text { SGIP1 } \\
\text { SNP }\end{array}$} & & \multirow{2}{*}{$\mathrm{n}=$} & \multicolumn{8}{|c|}{ P 300 Amplitude $(\mu \mathrm{V}) ;$ unadjusted $M \pm(S D)$} \\
\hline & & & FP-R & FP2-R & C3-R & C4-R & O1-R & $\mathrm{O} 2-\mathrm{R}$ & T3-R & T4-R \\
\hline \multirow{6}{*}{ rs10889635 } & & \multirow{6}{*}{$\begin{array}{l}49 \\
21 \\
57\end{array}$} & 3.55 & 3.51 & 2.61 & 2.94 & 3.05 & 2.97 & 2.42 & 2.82 \\
\hline & & & $(2.03)$ & $(1.93)$ & $(1.44)$ & $(1.11)$ & $(2.23)$ & $(2.10)$ & $(1.23)$ & (1.55) \\
\hline & $A A$ & & 3.58 & 3.22 & 3.98 & 4.37 & 3.56 & 3.20 & 4.39 & 3.96 \\
\hline & GG & & $(1.80)$ & $(1.36)$ & $(1.70)$ & $(1.11)$ & $(2.26)$ & $(2.18)$ & $(2.90)$ & (2.24) \\
\hline & $G A$ & & 3.69 & 3.19 & 4.20 & 3.95 & 3.49 & 3.35 & 4.30 & 3.91 \\
\hline & & & $(1.76)$ & (1.73) & $(1.84)$ & $(1.77)$ & (2.20) & (1.79) & (1.65) & (2.22) \\
\hline \multirow{6}{*}{ rs 6588207} & & \multirow{4}{*}{$\begin{array}{l}23 \\
45\end{array}$} & 3.39 & 3.08 & 3.11 & 2.75 & 3.78 & 3.09 & 3.65 & 3.99 \\
\hline & & & (2.08) & (1.38) & $(2.80)$ & (2.10) & (2.27) & (2.06) & (1.44) & (1.69) \\
\hline & $\begin{array}{l}A A \\
G G\end{array}$ & & 3.51 & 3.40 & 4.41 & 4.55 & 3.38 & 3.12 & 4.39 & 3.78 \\
\hline & GG & & (2.02) & (1.89) & (3.11) & $(2.90)$ & (2.49) & $(2.20)$ & $(3.02)$ & (2.21) \\
\hline & $G A$ & 59 & 3.79 & 3.35 & 3.60 & 3.17 & 3.11 & 3.26 & 3.31 & 3.12 \\
\hline & & & $(1.66)$ & $(1.81)$ & (1.28) & (1.61) & (2.03) & (1.79) & (1.64) & (1.94) \\
\hline
\end{tabular}

$\mathrm{M}$ - mean, SD - standard deviation

SGIP1 effects on P300 Latency.

There were no main effects of the individual SNPs on P300 latency (Tab. 5).

\section{Genetic Analyses}

Several SNPs located in the SGIP1 gene (chromosome 1p31.3) showed an association with resting theta electroencephalogram (EEG) power and, of these, rs6588207 and rs10889635 were reported as modestly associated with alcohol use disorders. It has been shown that the frequencies of the AA, GG and GA genotypes of rs10889635 and rs6588207 in participants were $38.3 ; 16.0 ; 45.7 \%$ and 18.5 ; $35.8 ; 45.7 \%$ in cases of alcoholics or $37.5 ; 25 ; 37.5 \%$ and $25 ; 37.5 ; 37,5 \%$ in controls, respectively. The rs6588207 and 
Table 5. P300 Latency by Genotype Group

\begin{tabular}{|c|c|c|c|c|c|c|c|c|c|c|}
\hline \multirow{2}{*}{$\begin{array}{l}\text { SGIP1 } \\
\text { SNP }\end{array}$} & & \multirow{2}{*}{$\mathrm{n}=$} & \multicolumn{8}{|c|}{ P 300 Latency $(\mu \mathrm{V}) ;$ unadjusted $\mathrm{M} \pm(\mathrm{SD})$} \\
\hline & & & FP-R & $\mathrm{FP} 2-\mathrm{R}$ & C3-R & C4-R & O1-R & $\mathrm{O} 2-\mathrm{R}$ & T3-R & $\mathrm{T} 4-\mathrm{R}$ \\
\hline \multirow{5}{*}{ rs10889635 } & \multirow{5}{*}{$\begin{array}{l}\mathrm{AA} \\
\mathrm{GG} \\
\mathrm{GA}\end{array}$} & \multirow{5}{*}{$\begin{array}{l}49 \\
21 \\
57\end{array}$} & \multirow{5}{*}{$\begin{array}{c}299.9 \\
(33.6) \\
303.4(26.9) \\
295.8 \\
(27.4)\end{array}$} & $\begin{array}{l}301.1 \\
(33.7)\end{array}$ & $\begin{array}{l}290.6 \\
(27.5)\end{array}$ & $\begin{array}{l}292.3 \\
(27.1)\end{array}$ & $\begin{array}{l}297.8 \\
(32.2)\end{array}$ & $\begin{array}{l}284.1 \\
(24.4)\end{array}$ & $\begin{array}{l}293.3 \\
(34.7)\end{array}$ & $\begin{array}{l}297.1 \\
(34.5)\end{array}$ \\
\hline & & & & 297.4 & 296.8 & 286.7 & 296.5 & 292.6 & 299.4 & 294.5 \\
\hline & & & & $(26.9)$ & (23.0) & (19.9) & $(28.5)$ & (26.6) & $(26.8)$ & (29.1) \\
\hline & & & & 303.9 & 297.8 & 300.1 & 302.3 & 303.4 & 301.1 & 298.4 \\
\hline & & & & $(30.0)$ & $(24.4)$ & $(28.2)$ & (28.8) & $(27.3)$ & $(25.6)$ & (29.1) \\
\hline \multirow{6}{*}{ rs 6588207} & \multirow{6}{*}{$\begin{array}{l}\text { AA } \\
\text { GG } \\
\text { GA }\end{array}$} & \multirow{6}{*}{$\begin{array}{l}23 \\
45 \\
59\end{array}$} & 304.6 & 300.3 & 298.7 & 288.1 & 303.6 & 297.6 & 296.7 & 295.7 \\
\hline & & & $(26.0)$ & $(31.0)$ & $(22.2)$ & $(24.2)$ & $(29.2)$ & $(29.7)$ & $(25.6)$ & (306) \\
\hline & & & 299.4 & 302.2 & 294.1 & 297.7 & 297.4 & 286.7 & 295.7 & 299.1 \\
\hline & & & (35.0) & $(33.7)$ & $(29.8)$ & $(30.3)$ & (33.1) & $(28.1)$ & $(37.2)$ & (35.7) \\
\hline & & & 295.9 & 302.0 & 293.9 & 295.4 & 299.7 & 298.5 & 299.8 & 296.5 \\
\hline & & & $(27.2)$ & $(29.3)$ & (23.5) & $(25.2)$ & $(28.4)$ & $(25.2)$ & (24.9) & (28.1) \\
\hline
\end{tabular}

M - mean, SD - standard deviation

rs10889635 genotype distribution in alcoholics groups and the control group are presented in Table 6.

Table 6. Genotype distribution of SGIP1 rs10889635 and rs6588207

\begin{tabular}{ccccccc}
\hline Genotype & \multicolumn{5}{c}{$\begin{array}{c}\text { gene SGIP1 } \\
\text { rs10889635 }\end{array}$} \\
\hline & $\begin{array}{c}\text { GR-1 } \\
\mathrm{n}=22\end{array}$ & $\begin{array}{c}\text { GR-2 } \\
\mathrm{n}=24\end{array}$ & $\begin{array}{c}\text { GR-3 } \\
\mathrm{n}=31\end{array}$ & $\begin{array}{c}\mathrm{GR}-4 \\
\mathrm{n}=26\end{array}$ & $\begin{array}{c}\text { GR-5 } \\
\mathrm{n}=24\end{array}$ & $\begin{array}{c}\text { Control } \\
\mathrm{n}=25\end{array}$ \\
\hline AA (\%) & 64,3 & 46,2 & 40,0 & 34,7 & 12,5 & 40,0 \\
\hline GG (\%) & 14,3 & 0,0 & 20,0 & 21,7 & 18,7 & 26,6 \\
\hline AG (\%) & 21,4 & 53,8 & 40,0 & 43,6 & 67,8 & 33,4 \\
\hline & & & $\mathrm{rs} 6588207$ & & \\
\hline AA (\%) & 14,3 & 15,4 & 20.0 & 21,7 & 18,7 & 26,6 \\
\hline GG (\%) & 64,3 & 30,8 & 40.0 & 34,7 & 12,5 & 40,0 \\
\hline AG (\%) & 21,4 & 53,8 & 40.0 & 43,6 & 67.8 & 33,4 \\
\hline
\end{tabular}

The genotype frequencies of the control samples and each of the alcoholic groups were all consistent with the HardyWeinberg equilibrium for rs10889635 and rs6588207.

A significantly increased risk of alcoholic disorder was observed among the participants with homozygous variant genotype (AA) (adjusted OR: 1.63, 95\% CI: 1.042.55), compared with those carrying GG genotype, which means that the 10889635 AA genotype may be a risk factor of alcoholism. Similarly, we examined the rs189037 AA genotype carriers in the study groups, but no significant associations $(\mathrm{P}>0.05)$ were found (Tab. 7$)$.

Table 7. Genotype distribution of SGIP1 rs10889635 and rs6588207 and their associations with alcoholism

\begin{tabular}{lccccc}
\hline & Genotype & Case (\%) & Control (\%) & OR $(95 \% \mathrm{Cl})^{\text {a }}$ & $\mathrm{P}=$ \\
\hline rs10889635 & & & & & \\
\hline Total & GG & $21(16.0)$ & $10(40)$ & 1.0 & \\
\hline Population & GA & $57(45.7)$ & $7(28)$ & $1.23(0.92-1.66)$ & 0.162 \\
\hline & AA & $49(38.3)$ & $8(32)$ & $\mathbf{1 . 6 3 ( 1 . 0 4 - 2 . 5 5 )}$ & $\mathbf{0 . 0 3 2}^{*}$ \\
\hline rs6588207 & & & & & \\
\hline & GG & $45(35.8)$ & $7(28)$ & 1.0 & \\
\hline & GA & $59(45.7)$ & $10(40)$ & $1.11(0.64-1.97)$ & 0.686 \\
\hline & AA & $23(18.5)$ & $8(32)$ & $1.21(0.77-1.89)$ & 0.411 \\
\hline
\end{tabular}

a $\mathrm{OR}$ - odds ratios; $\mathrm{Cl}$ - confidence interval; ${ }^{*} \mathrm{P}<0.05$

\section{DISCUSSION}

The present study demonstrated a possible association of target evoked theta P300 and of alcohol dependence with SNPs from the intron gene SGIP1 in the region of rs10889635.

SGIP1 functions as an endocytic protein that affects signaling by receptors in neuronal systems involved in energy homeostasis, via its interaction with endophilins. However, its function is not fully understood [8]. The study by Hodgkinson et al. [6], showed an association between several SNPs located in the SGIP1 gene (chromosome 1p31.3) and resting theta electroencephalogram (EEG) power, as well as an association between the majority of these same SNPs and alcohol use disorders in a sample of Plains Indians. This association appeared to be generalized to alcohol use disorders, for which EEG power is a potential endophenotype. However, in later studies carried out on a large, diverse sample, no evidence of association of the previously implicated SGIP1 SNPs with either alcohol dependence or theta EEG power was found [9]. In this study, the authors analyzed the 8 SNPs, including rs10889635 and rs6588207, in individuals of European and/ or African ancestry.

The present study included individuals of Polish ancestry with 3 generations (parents, siblings, spouses, marrying into the family, and children). The results showed an increased risk of alcoholic disorder in participants with homozygous variant genotype (AA), compared with those carrying the GG genotype in SGIP1 SNPs (rs10889635). This relationship did not occur in individual groups of alcoholics, nor in the case of SNP in the region of rs6588207.

The difference in findings between the studies should be considered in the context of the differences in investigated populations. The participants in our study were individuals of Polish ancestry with 3 generations genetically closely related. Moreover, with respect to the small sample of people with genetic kinship and alcoholism, our conclusions need to be confirmed by a subsequent study on a larger group of family-related subjects.

Next, we investigated the effects of the SGIP1gene on brain neurophysiology by examining associations between 2 individual SNPs in the SGIP1 gene and P300 amplitude and latency. We revealed that SNP rs10889635 had a significant effect on P300 amplitude in the central and temporal regions. The reduced P300 amplitude was in AA carriers, in comparison to both carriers of GG and GA alleles. Thus, the results suggest that the G allele of SNP rs10889635 confers 
increased P300 amplitude in the central and temporal regions in alcoholics.

In addition, the association between P300 amplitude and the SNPs investigated here suggests that variation in SGIP1 gene could influence the cognitive processing of auditory stimuli.

In addition, no significant association was found between SGIP1 polymorphisms and alcoholism in the particular groups of alcoholics studied (results not shown).

As described earlier, these results are not consistent with the results of studies by Derringer et al. [9], in which no evidence was found for an association between SNP rs10889635 in SGIP1 and theta EEG power, with P values between $0.40-0.90$. These differences should be considered in the context of the differences between the studied groups. In this study, the analysis included individuals of Polish origin in a small and genetically homogenous sample, while the findings by Derringer et. al., were reported for a large $(n=3988)$, ethnically diverse group of individuals with alcohol dependence, but genetically unrelated. However, as mentioned earlier, our conclusions need to be confirmed in a large, similar study. In addition, Chen et al. [10] reported significant associations between the P300 amplitude and visual targets together with the alcohol dependence diagnosis related with multiple SNPs and the corticotrophin-releasing hormone receptor 1 (CRHR1) gene. Also, genetic linkage and association with the muscarinic acetylcholine receptor M2 (CHRM2) and theta or delta EROs P300 were reported [11].

In a study by Hill et al. [12], auditory P300 trajectories associated with high familial risk for alcohol dependence (AD) were found in males but not females in the 8 12-year-old group. In this study, one SNP in CHRM2 gene, rs1824024, was found to be associated with the trajectory characterized by a lower P300 amplitude. In addition, SNPs in CHRM2 gene have been found with comorbid alcohol dependence and depression [13] and comorbid alcohol and drug dependence [14]. Apart from the CHRM2 gene, GABAergic and glutamatergic receptor genes were also found to be associated with alcoholism-related phenotypes. In a study analyzing frontal theta ERO in the visual oddball task as a neurophysiological phenotype phenomenon, a significant association with several SNPs in the KCNJ6 gene was found. The KCNJ6 gene encodes the GRK2 protein, which is widely distributed in the brain and is important in dopaminergic, gabaergic and glutamatergic synaptic transmission $[15,16]$.

Next, we found that the latency of the auditory P300 response did not differ significantly among the groups of alcoholics, compared to the control group.

The lack of significant familial correlations in P300 latency, particularly in groups with high rates of psychotic illnesses, may be surprising in view of the previous research which demonstrated a relationship between organic brain damage and increased latency of P300 [4, 17].

In contrast to latency, the amplitude of the auditory P300 response differed considerably among groups of alcoholics in the frontal, central and temporal areas of the brain, and it was lower in the studied brain regions in alcoholics in comparison to non-alcoholics.

A lot of research has demonstrated that alcoholics consistently manifest significantly lower P300 amplitudes under a variety of task conditions and in both genders [4, 17]. Moreover, the reduced $\mathrm{P} 300$ amplitude is more closely related to the number of first-degree alcoholic relatives more than the drinking history of an alcoholic [18] or of high-risk (HR) individuals [19]. Furthermore, a reduced amplitude of the P300 in prepubescence has been shown to predict later alcohol abuse in adolescence [20]. Low P300 amplitudes have been reported in both male and female children, adolescent, and young offspring of alcoholics prior to any exposure to alcohol [4]. However, other older studies are less convincing or do not support this hypothesis [21, 22].

In our study, in the young adult group (GR-1) there was no statistical difference in amplitude of P300 response with control subjects in all studied brain regions, in comparison with non-alcoholics. However, people with this subtype (GR-1) had a low rate of family alcoholism (22.7\%) and co-occurring psychoactive drug abuse. Furthermore, the young antisocial subtype (GR-2), also consisting of young individuals who mostly (62.5\%) had a positive family history of alcoholism, already had a low amplitude of P300 response. Similarly, family history was significantly and selectively associated with lower P300 amplitudes in a group of young adult African American men and women, and current use of marijuana and alcohol did not modify P300 amplitudes [23]. Taken together, our results are consistent with the majority of views on this topic.

Low P300 amplitude found only in alcoholics with a subtype of 2 (GR-2) and 3 (GR-3) in the central area of the brain. Reduced P300 amplitude in alcoholics with a subtype of 4 (GR-4) and 5 (GR-5) were found in the central area as well as in temporal areas of the brain. Alcoholics with subtype of 4 and 5 had an early onset of drinking (average about 15 years of age), high rates of psychiatric disorders (27 and 33\%), and more than half (61 and 75\%) had close relatives who were alcoholics and/or smoked tobacco $(69$ and 79\%). Any brain disorder affecting cognitive processes may reduce the P300 amplitude and increase the latency [24]. This may be contrasted with decreased amplitudes that are typically observed in psychopathological conditions such as schizophrenia, bipolar disorder, Alzheimer's, depression and alcohol disorders [25].

In conclusion, we investigated the potential associations between single nucleotide polymorphisms (SNPs) located in the SGIP1 gene (chromosome 1p31.3) and ERP quantitative traits, and found a significant association between targetevoked theta P300 and alcohol dependence with SNPs from the gene SGIP1 in the region of rs10889635. However, due to the small sample of people with genetic kinship and alcoholism, our conclusions need to be confirmed by a subsequent study on a larger group of family-related subjects.

\section{Acknowledgements}

This study was supported by the National Science Centre, Krakow, Poland (Grant No. NN404316940).

\section{REFERENCES}

1. Kendler KS, Prescott CA, Myers J, Neale MC. The structure of genetic and environmental risk factors for common psychiatric and substance use disorders in men and women. Arch Gen Psychiatry 2003; 60: 929-937.

2. Sygit K, Kołłątaj W, Wojtyła A, Sygit M, Bojar I, Owoc A. Engagement in risky behaviours by 15-19-year-olds from Polish urban and rural areas. Ann Agric Environ Med. 2011; 18: 404-409.

3. Cservenka A. Neurobiological phenotypes associated with a family history of alcoholism. Drug Alcohol Depend. 2016; 158: 8-21. 
4. Porjesz B, Rangaswamy M, Kamarajan C, Jones KA, Padmanabhapillai A, Begleiter $\mathrm{H}$. The utility of neurophysiological markers in the study of alcoholism. Clin. Neurophysiol. 2005; 116: 993-1018.

5. Porjesz B, Rangaswamy M. Neurophysiological endophenotypes, CNS disinhibition, and risk for alcohol dependence and related disorders. Scientific World Journal 2007; 7: 131-141.

6. Hodgkinson CA, Enoch MA, Srivastava V, Cummins-Oman JS, Ferrier C, Iarikova P, et al. Genome-wide association identifies candidate genes that influence the human electroencephalogram. Proc Natl Acad Sci. 2010; 107: 8695-8700.

7. Cservenka A, Nagel BJ. Risky decision-making: an fMRI study of youth at high risk for alcoholism. Alcohol Clin Exp Res. 2012; 36: 604-615.

8. Uezu A, Horiuchi A, Kanda K, Kikuchi N, Umeda K, Tsujita K, et al. SGIP1alpha is an endocytic protein that directly interacts with phospholipids and Eps15. J Biol Chem. 2007; 282: 26481-26489.

9. Derringer J, Krueger RF, Manz N, Porjesz B, Almasy L, Bookman E, et al. Nonreplication of an association of SGIP1 SNPs with alcohol dependence and resting theta EEG power. Psychiatr Genet. 2011; 21: 265-266.

10. Chen AC, Manz N, Tang Y, Rangaswamy M, Almasy L, Kuperman $\mathrm{S}$, et al. Single-nucleotide polymorphisms in corticotropin releasing hormone receptor 1 gene (CRHR1) are associated with quantitative trait of event-related potential and alcohol dependence. Alcohol Clin Exp Res. 2010; 34: 988-996.

11. Jones KA, Porjesz B, Almasy L, Bierut L, Dick D, Goate A, et al. A cholinergic receptor gene (CHRM2) affects event-related oscillations. Behav Genet. 2006; 36: 627-639.

12. Hill SY, Jones BL, Holmes B, Steinhauer SR, Zezza N, Stiffler S. Cholinergic receptor gene (CHRM2) variation and familial loading for alcohol dependence predict childhood developmental trajectories of P300. Psychiatry Res. 2013; 209: 504-511.

13. Wang JC, Hinrichs AL, Stock H, Budde J, Allen R, Bertelsen S, et al. Evidence of common and specific genetic effects: Association of the muscarinic acetylcholine receptor M2 (CHRM2) gene with alcohol dependence and major depressive syndrome. Hum Mol Gen. 2004; 13: $1903-1911$
14. Dick DM, Agrawal A, Wang JC, Hinrichs A, Bertelsen S, Bucholz KK et al. Alcohol dependence with comorbid drug dependence: Genetic and phenotypic associations suggest a more severe form of the disorder with stronger genetic contribution to risk. Addiction 2007; 102: 1131-1139.

15. Kang SJ, Rangaswamy M, Manz N, Wang JC, Wetherill L, Hinrichs $\mathrm{T}$, et al. Family-based genome-wide association study of frontal theta oscillations identifies potassium channel gene KCNJ6. Genes Brain Behav. 2012; 11: 712-719.

16. Saenz del Burgo L, Cortes R, Mengod G, Zarate J, Echevarria E, Salles J. Distribution and neurochemical characterization of neurons expressing GIRK channels in the rat brain. J Com Neurol. 2008; 510: 581-606.

17. Polich J, Ladish C, Bloom FE. P300 assessment of early Alzheimer's disease. Electroencephalogr Clin Neurophysiol. 1990; 77: 179-89.

18. Cohen HL, Wang W, Porjesz B, Begleiter H. Auditory P300 in young alcoholics: Regional response characteristics. Alcohol Clin Exp Res. $1995 ; 19,469-475$.

19. Benegal V, Jain S, Subbukrishna DK, Channabasavanna SM. P300 amplitudes vary inversely with continuum of risk in first degree male relatives of alcoholics. Psych Gen. 1995; 5: 149-156.

20. Hill SY, Steinhauer S, Lowers L, Locke J. Eight-year longitudinal follow-up of P300 and clinical outcome in children from high-risk for alcoholism families. Biol Psychiatry 1995; 37: 823-827.

21. Bauer LO, Hesselbrock VM. P300 decrements in teenagers with conduct problems: implications for substance abuse risk and brain development. Biol Psychiatry 1999; 46: 264.272.

22. Rodriguez-Holguin SC, Corral M, Cadaveira F. Visual and auditory event-related potentials in young children of alcoholics from high- and low-density families. Alcohol Clin Exp Res. 1998; 22: 87-96.

23. Ehlers CL, Phillips E, Sweeny A, Slawecki CJ. Event-related potential responses to alcohol-related stimuli in African-American young adults: relation to family history of alcoholism and drug usage. Alcohol Alcohol. 2003; 38: 332-338.

24. Polich J, Herbst KL. P300 as a clinical assay: rationale, evaluation, and findings. Int J Psychophysiol. 2000; 38: 3-19.

25. Polich J, Pollock VE, Bloom FE. Meta-analysis of P300 amplitude from males at risk for alcoholism. Psychol Bull. 1994; 115: 55-73. 